\title{
Insulin, pioglitazone and Zingiber officinale administrations improve proliferating cell nuclear antigen immunostaining effects on diabetic and insulin resistant rat testis
}

\author{
Adesina Paul Arikawe* ${ }^{a *}$, Adetola Olubunmi Daramola ${ }^{\mathrm{b}}$, Ibiyemi Ibitola Olatunji-Bello ${ }^{\mathrm{c}}$, Leonard Fidelis Obika \\ ${ }^{a}$ Department of Physiology, College of Medicine, University of Lagos, Nigeria \\ ${ }^{b}$ Department of Anatomic and Molecular Pathology, College of Medicine, University of Lagos, Nigeria \\ ${ }^{c}$ Department of Physiology, Lagos State University College of Medicine, Ikeja, Lagos State, Nigeria \\ ${ }^{d}$ Department of Physiology, College of Medical Sciences, University of Benin, Benin City, Edo State, Nigeria
}

\section{ARTICLE INFO $\quad$ ABSTRACT}

\section{Article History}

Received $\quad 28 / 09 / 2012$

Accepted $\quad 03 / 11 / 2012$

\section{* Correspondence to:}

Adesina Paul Arikawe

Department of Physiology,

Faculty of Basic Medical Science

College of Medicine of the University of

Lagos, Idi-Araba, Lagos PMB 12003,

Lagos. Nigeria

e-mail: arikawepaul2002@yahoo.co.uk

\section{Keywords:}

Diabetes

Ginger

Insulin

PCNA

Pioglitazone

Spermatogenesis

\begin{abstract}
This study accessed the effects of hypoglycaemic drugs on spermatogenesis in diabetic and insulin resistant rat testis following proliferating cell nuclear antigen (PCNA) immunostaining. Male adult Sprague-Dawley rats (120-140 g) were randomly divided into 5 groups. Group 1 served as control group; fed on normal rat pellets. Group 2 served as streptozotocin-insulin treated group; received a single dose IP Injection of streptozotocin $45 \mathrm{mg} / \mathrm{kg} \mathrm{BW}$ in $\mathrm{Na}^{+}$citrate buffer $\mathrm{pH} 4.5$ and treated with insulin sub-cutaneously. Group 3 served as streptozotocin-ginger treated group; received a single dose IP injection of streptozotocin as in group 2 above and treated with $500 \mathrm{mg} / \mathrm{Kg}$ ginger extract orally. Group 4 served as Insulin resistant-pioglitazone treated group; fed ad libitum on a special diet containing $25 \%$ fructose mixed with $75 \%$ normal rat chow $(\mathrm{w} / \mathrm{w})$ and treated with Pioglitazone $15 \mathrm{mg} / \mathrm{kg}$ orally. Group 5 served as Insulin resistant-ginger treated group; fed ad libitum on a special diet as in group 4 above, and also treated with $500 \mathrm{mg} / \mathrm{Kg}$ ginger extract orally. Following hyperglycemia confirmation, animals were perfused with 4\% Paraformaldehyde (PFA). Testes were isolated, and fixed in 4\% PFA overnight, embedded in paraffin, $5 \mu \mathrm{m}$ thick sections were made and mounted on poly-L-lysine coated slides. Immunohistochemical staining was carried out on positively charged slides using PCNA as primary antibody. The results showed that insulin, pioglitazone and ginger administrations ameliorated the diabetic and insulin resistant effects on spermatogenesis in male rats. The precise interplay of hypothalamic, pituitary and steroid hormones is subject for further study in these group of animals.
\end{abstract}

J. Exp. Clin. Med., 2013; 30:49-55

(C) 2013 OMU

\section{Introduction}

The testis is a tissue of high proliferative activity in which, sperm cells (spermatozoa) are produced from stem cells (spermatogonia) by two consecutive steps of cell multiplication and spermatid cytodifferentiation (Stephan et al., 1996). Diabetes mellitus is a common health problem with many functional and structural complications (Todd Cade, 2008). The World Health Organization (WHO) in year 2000 reported that 177 million people were affected by diabetes worldwide and projected that by 2025 , this figure will rise to over 300 million (WHO, 2002). Likewise, Zimmet et al., (2001) also projected that this figure will be doubled in the next 20 years.

Insulin is the major hormone controlling critical energy functions such as glucose and lipid metabolism. Colosia et al., (1988) in their work showed that when diabetic rats were treated with insulin, the activities of the bifunctional enzyme 6-phosphofructo-2-kinase/fructo-2,6-diphosphate were restored back to normal after falling to $20 \%$ of Control values and this fall was associated with insulin deficiency (Dall'Aglio et al., 1986). Pioglitazone is a potent insulin sensitizer, which binds to the peroxisome-proliferator activated receptor-gamma, resulting in enhanced muscle, liver, and adipose tissue sensitivity to insulin, with a resultant decline in fasting and postprandial plasma glucose levels (Miyazaki et al., 2002; Matthews et al., 2005; Miyazaki and De Fronzo, 2008). Pioglitazone has also been reported to augment beta cell function (Gastaldelli et al., 2007). 
Ginger (Zingiber officinale) is a commonly used spice in the African Kitchen and has been used as spice for over 2000 years (Bartley and Jacobs, 2000). It is cultivated in the tropics for its edible rhizome at about 10 months of age, with the root stocks serving culinary and medicinal purposes (Portnoi et al., 2003). The culinary use is as spice and food ingredient while for its medicinal use, research on rats suggests that ginger may be useful for treating diabetes (Kim et al., 2003). Al-Amin et al., (2006) observed that aqueous ginger juice has anti-diabetic and hypolipidaemic properties. Akhani et al. (2004) also observed that ginger juice exhibits hypoglycemic activity in both normal and Type 1 diabetic rats.

Proliferating Cell Nuclear Antigen (PCNA) is a $36 \mathrm{kDa}$ non-histone protein found in the nucleus that plays a role in the initiation of cell proliferation by mediating DNA polymerase, which plays an integral role in the eukaryotic cell cycle and is essential for cellular DNA synthesis. PCNA is a primary antibody; its levels are elevated in the S, G2, and $\mathrm{M}$ phases of cell mitosis in normal and malignant tissues. Its biological half-life is 20 hours and its expression has a broad correlation with mitotic activity and can be used as a marker for cell proliferation (Bravo and Macdonald-Bravo, 1987, Waseem and Lane, 1990; van Dierendonck et al., 1991; Dervan et al., 1992; Linden et al., 1992). PCNA is useful for the diagnosis of germinal arrest because there are significantly reduced PCNA levels in germinal arrest, which is an indication of DNA synthesis deterioration (Zeng et al., 2001).

Diabetes is also caused by complicated factors e.g. absolute insulin deficiency and relative insulin deficiency i.e. insulin resistance and its damage to the male reproductive system has been reported to threaten men's health (Zhao et al., 2004). Male sexual and reproductive functions are one of the mammalian systems that are clearly impaired by Diabetes (Guneli et al., 2008; Jelodar et al., 2010). In line with this view, Arikawe et al., (2006) reported that diabetes mellitus and insulin resistance affect semen parameters and impair spermatogenesis in male rats. Furthermore these same authors recently reported that streptozotocin-induced diabetes and insulin resistance reduced PCNA index, mean seminiferous tubular diameter and testicular diameter in adult male rats testes (Arikawe et al. 2012). Thus, the present study aimed to assess PCNA immunostaining effects in streptozotocininduced and insulin resistant diabetic rat testis after treatment with insulin, pioglitazone and Zingiber officinale.

\section{Experimental procedure}

Thirty-five adult male Sprague-Dawley rats, whose average weight ranged between 120-140 g were procured from a breeding stock maintained in the Laboratory Animal Department of the College of Medicine, University of Lagos. The animals were housed in clear polypropylene cages lined with wood chip beddings and were allowed to acclimatize in the Physiology Department animal laboratory with an ambient temperature maintained between $26^{\circ} \mathrm{C}-28^{\circ} \mathrm{C}$ for a period of one week before the beginning of the study. The rats were also maintained under standard colony photoperiodic conditions with a 12-hour light/12-hour dark cycle (lights on at 7:00 hour) and all animals had unrestricted (ad libitum) access to water. The rats were randomly divided into 5 groups (of 7 animals each of similar weight).

Group 1 served as Control group, fed on normal rat chow throughout experimental period of 16 weeks. Group 2 served as Streptozotocin-insulin treated group; fed on normal rat chow; received a single dose IP (intraperitoneal) injection of Streptozotocin, $45 \mathrm{mg} / \mathrm{kg}$ body weight (Guneli et al., 2008) freshly dissolved in $\mathrm{Na}^{+}$citrate buffer $\mathrm{pH} 4.5$ for 4 weeks, and also treated with $0.5-1$ IU Isophane Insulin sub-cutaneously for additional 4 weeks. Group 3 served as Streptozotocin-ginger treated group; fed on normal rat chow; received Streptozotocin injection as in Group 2 above, and also treated with $500 \mathrm{mg}$ daily of ginger extract $/ \mathrm{Kg}$ body weight orally for additional 4 weeks. This chosen dosage of $500 \mathrm{mg}$ ginger extract/kg body weight was previously found to be effective and non-toxic in rats (Thomson et al., 2002; Alnaqeeb et al., 2003; Morakinyo et al., 2008). Blood samples were collected from the tail vein 48 hours after Streptozotocin injection to confirm hyperglycemia using Dextrostix Test Strips (Bayer Corporation, U.K.) following the glucose oxidase method (Hugget and Nixon, 1957). Streptozotocin administration was not prolonged for more than 4 weeks without treatment because the glycemic levels were very high, and as time passed the animals became weaker (Watala et al., 2009) and eventually resulted in mortality.

Group 4 served as Insulin resistant-pioglitazone treated group; fed ad libitum on a special diet containing $25 \%$ fructose mixed with $75 \%$ normal rat chow (w/w) for 4 weeks (Arikawe and Olatunji-Bello, 2004) and continued till the $12^{\text {th }}$ week (Arikawe et al., 2006); and also treated with Pioglitazone $15 \mathrm{mg} / \mathrm{kg}$ orally for additional 4 weeks. Group 5 served as Insulin resistant-ginger treated group; fed ad libitum on a special diet as in group 4 above, and also treated with 500mg daily of ginger extract/Kg body weight orally for additional 4 weeks. Hyperglycemia was confirmed at the 16th week using Dextrostix Test Strips (Bayer Corporation, U.K.) following the glucose oxidase method (Hugget and Nixon, 1957).

Polydipsia, polyuria and polyphagia were observed (Jelodar et al., 2010) and confirmed in the experimental groups (Groups 2 to 5). All animals had free access to drinking water throughout the duration of the study. Rats with blood glucose concentration above $250 \mathrm{mg} / \mathrm{dl}$ were used as Type I diabetic rats (Akingba and Burnett, 2001), while rats with blood glucose concentration above $200 \mathrm{mg} / \mathrm{dl}$ were used as Insulin resistant diabetic rats (Catena et al., 2003). Rats were weighed weekly throughout the duration of the experiment and animals were monitored for general health during the treatment period. All the procedures were performed in accordance with the guidelines of the College Ethical Committee on the use of laboratory animals for research.

\section{Methodology}

At the end of each experimental period, following hyperglycaemia confirmation, the following analyzes were carried out (i) Haematologic analysis for Glycosylated Haemoglobin levels (ii) Immunohistochemical staining using PCNA as primary antibody.

\section{Immunohistochemical staining}

At the end of each experimental period, following hyperglycaemia confirmation, animals were perfused using standard Perfusion Techniques in the laboratory with 4\% Paraformaldehyde (PFA), this was carried out at high stringency. Summarily before removal of the testes, the rats were deeply 
anaesthetized with diethly ether and pain suppressed using sodium pentobarbitone. Rats were then perfused transcardially first with Dulbecco Phosphate Buffer Saline (PBS) and followed by $4 \%$ PFA in PBS. Successful perfusion was confirmed by spontaneous movement (formalin dance), rapid tail rise, stretching, lightened colour of liver and pale testis. Testes were isolated, weighed and fixed in 4\% PFA overnight; they were passed through ascending series of ethanol baths, embedded in paraffin, $5 \mu \mathrm{m}$ thick sections of paraffinembedded samples were made using the microtome machine and mounted on poly-L-lysine coated slides i.e. positively charged slides. Routine deparafinization and rehydration steps were carried out, followed by antigen retrieval steps (ARs). Antigen retrieval (or antigen recovery) is performed to expose or retrieve antigens which have become masked by the tissue fixation process.

Following successful antigen retrieval steps, immunohistochemical staining was carried out on the positively charged slides using the PCNA as primary antibody. The slides were incubated in 1\% Bovine Serum Albumin in PBS (blocking solution) for 30 minutes at room temperature and washed three times in PBS; slides were incubated in pre-diluted primary antibody (PCNA, Invitrogen USA) for 60 minutes at room temperature in a humidified chamber and then washed with PBS twice for 5 minutes each.

Further immunostaining was performed using labeled Streptavidin Horse Radish Peroxidase (HRP) for another 60 minutes at room temperature in a humidified chamber and then washed with PBS twice for 5 minutes each; final step of antibody localization of peroxidase deposition was achieved by using Diaminobenzidine- $\mathrm{H}_{2} \mathrm{O}_{2}$ (DAB, Dako) for chromogenic reaction and subsequently washed in running water for another 5 minutes; this was followed by counterstaining with Harris' Haematoxylin and Eosin, dehydrated in alcohols to xylene and finally mounted using Dibutylpthalate Xylene (DPX) with coverslip. As a control for method specificity, in negative control slide, the step using primary antibody (PCNA) was omitted and slides were viewed under the light microscope.

Ten seminiferous tubules were counted in each slide; cells with brown nuclear staining were considered positive (Altay et al., 2003). Both stained and non-stained germ cells were counted and the ratio of stained cells to the total number germ cells, i.e. PCNA index and density was calculated (Altay et al., 2003). The average PCNA index in each case was obtained by dividing the sum of all PCNA indices by the number of seminiferous tubules in which the calculation was carried out. Testicular diameter (TD) was measured di- rectly by cutting testes vertically into two and largest TD then measured (Altay et al., 2003). Mean Seminiferous Tubule Diameter (MSTD) was evaluated by measuring the smallest diameter of ten tubuli on ten randomly selected fields using an ocular micrometer at x400 magnification (Altay et al., 2003).

\section{Statistical analysis}

All data are presented as mean \pm standard error of mean (SEM). The data was analyzed using One-way ANOVA (analysis of variance) followed by Student-Newman-Keuls post-hoc test. Level of statistical significance was taken at $p<0.05$. The image $\mathrm{J}$ software package was used to analyze the immunohistochemical slides.

\section{Results}

Fasting blood glucose concentration (mg/dl) and Glycosylated haemoglobin level (\%) in control rats were $(91.4 \pm 2.1 \mathrm{mg} /$ dl, $5.5 \pm 0.2 \%)$; Streptozotocin-insulin treated $(283.4 \pm 13.1 \mathrm{mg} /$ dl, $6.6 \pm 0.1 \%)$; Streptozotocin-ginger treated $(423.3 \pm 18.6 \mathrm{mg} /$ dl, $6.9 \pm 0.2 \%$; Insulin resistant-pioglitazone treated $(101.5 \pm 2.3 \mathrm{mg} / \mathrm{dl}, 7.8 \pm 0.3 \%)$; and Insulin resistant-ginger treated rats $(117.1 \pm 2.5 \mathrm{mg} / \mathrm{dl}, 7.8 \pm 0.1 \%)$ respectively. These were significantly lower $(\mathrm{p}<0.001)$ in the control rats compared to rats in the experimental groups with the exception of insulin resistant-pioglitazone and insulin-resistant ginger treated groups (Table 1).

Mean Seminiferous Tubular Diameter $(\mu \mathrm{m})$ of the left testis in the Control rats was $(201.5 \pm 6.4 \mu \mathrm{m})$; Streptozotocin-insulin treated $(160.0 \pm 7.6 \mu \mathrm{m})$; Streptozotocin-ginger treated $(175.4 \pm 10.1 \mu \mathrm{m})$; Insulin resistant-pioglitazone treated $(150.0 \pm 6.9 \mu \mathrm{m})$; and Insulin resistant-ginger treated rats $(162.0 \pm 3.0 \mu \mathrm{m})$. Thus, with the exception of Streptozotocinginger treated group, MSTD of the left testis was significantly lower $(\mathrm{p}<0.05)$ in all the other experimental groups compared to the Control group. On the other hand, MSTD of the right testis was significantly lower $(\mathrm{p}<0.001)$ in the Streptozotocin-insulin treated $(160.6 \pm 7.6 \mu \mathrm{m})$; Streptozotocin-ginger treated $(167.1 \pm 9.9 \mu \mathrm{m})$; Insulin resistant-pioglitazone treated $(150.1 \pm 7.0 \mu \mathrm{m})$; and Insulin resistant-ginger treated rats $(163.0 \pm 3.0 \mu \mathrm{m})$ Compared to rats in the control $(219.8 \pm 9.4$ $\mu \mathrm{m})$ group. Likewise, MSTD of both testes was significantly lower $(p<0.001)$ in the Streptozotocin-insulin treated $(160.1 \pm 5.2 \mu \mathrm{m})$; Streptozotocin-ginger treated $(175.4 \pm 7.6$ $\mu \mathrm{m})$; Insulin resistant-pioglitazone treated $(150.1 \pm 4.7 \mu \mathrm{m})$; and Insulin resistant-ginger treated rats $(163.0 \pm 2.0 \mu \mathrm{m}) \mathrm{com}-$ pared to rats in the Control $(210.6 \pm 6.1 \mu \mathrm{m})$ group.

Testicular Diameter $(\mathrm{mm})$ in the Control rats was $(15.7 \pm$

Table 1. Fasting Blood Glucose concentration, Glycosylated Haemoglobin level, MSTD, and TD in Control, Streptozotocin-Insulin, Streptozotocin-Ginger, Insulin resistant-Pioglitazone, and Insulin resistant-Ginger groups

\begin{tabular}{|c|c|c|c|c|c|}
\hline & Control & Streptozotocin-Insulin & $\begin{array}{c}\text { Streptozotocin- } \\
\text { Ginger }\end{array}$ & $\begin{array}{l}\text { Insulin resistant- } \\
\text { Pioglitazone }\end{array}$ & $\begin{array}{c}\text { Insulin resistant- } \\
\text { Ginger }\end{array}$ \\
\hline FBG mg/dl & $91.4 \pm 2.1$ & $283.4 \pm 13.1 \dagger \dagger^{\mathrm{a}}$ & $423.3 \pm 18.6+\div$ & $101.5 \pm 2.3$ & $117.1 \pm 2.5$ \\
\hline HbA1c (\%) & $5.5 \pm 0.2$ & $6.6 \pm 0.1 \dagger$ & $6.9 \pm 0.2 \dagger$ & $7.8 \pm 0.3 \dagger \# *$ & $7.8 \pm 0.1 \dagger \# *$ \\
\hline MSTD $(\mu \mathrm{m})$ Left Testis & $201.5 \pm 6.4$ & $160.0 \pm 7.6 \alpha$ & $175.4 \pm 10.1$ & $150.0 \pm 6.99$ & $162.0 \pm 3.0 \alpha$ \\
\hline MSTD $(\mu \mathrm{m})$ Right Testis & $219.8 \pm 9.4$ & $160.6 \pm 7.6 \dagger$ & $167.1 \pm 9.9 \dagger$ & $150.1 \pm 7.0 \dagger$ & $163.0 \pm 3.0 \dagger$ \\
\hline MSTD $(\mu \mathrm{m})$ Both Testes & $210.6 \pm 6.1$ & $160.1 \pm 5.2 \dagger$ & $175.4 \pm 7.6 \dagger$ & $150.1 \pm 4.7 \dagger^{*}$ & $163.0 \pm 2.0 \dagger$ \\
\hline Testicular Diameter (mm) & $15.7 \pm 0.4$ & $13.2 \pm 0.5 \dagger$ & $13.5 \pm 0.6 \dagger$ & $11.8 \pm 0.6 \dagger$ & $12.8 \pm 0.6 \dagger$ \\
\hline
\end{tabular}

All results presented in mean \pm SEM

$\dagger \mathrm{P}<0.001, \mathbb{\top}<0.01, \alpha \mathrm{P}<0.05$ Vs Control; \#P<0.001 Vs Streptozotocin-Insulin; $* \mathrm{P}<0.001$ Vs Streptozotocin-Ginger;

${ }^{\text {a }}<<0.001$ Vs Insulin resistant-Ginger; $\leftarrow \mathrm{P}<0.001$ Vs Insulin resistant- Pioglitazone

Footnote: Mean Seminiferous Tubule Diameter (MSTD); Testicular Diameter (TD); Glycosylated Haemoglobin level (HbA1c (\%) 
Table 2. PCNA index and Numerical density in Control, Streptozotocin-Insulin, Streptozotocin-Ginger, Insulin resistant-Pioglitazone, and Insulin resistant-Ginger groups

\begin{tabular}{|c|c|c|c|c|c|}
\hline & Control & Streptozotocin-Insulin & $\begin{array}{l}\text { Streptozotocin- } \\
\text { Ginger }\end{array}$ & Insulin resistant- Pioglitazone & $\begin{array}{c}\text { Insulin resistant- } \\
\text { Ginger }\end{array}$ \\
\hline PCNA Index (\%) Left Testis & $82.8 \pm 0.1$ & $64.5 \pm 0.2 \dagger$ & $65.4 \pm 0.1 \dagger \#$ & $67.3 \pm 0.2 \dagger \# * a$ & $34.5 \pm 0.2 \dagger * \#$ \\
\hline PCNA Index (\%) Right Testis & $88.4 \pm 0.1$ & $64.8 \pm 0.1 \uparrow$ & $64.5 \pm 0.1 \uparrow$ & $67.2 \pm 0.1 \dagger \# * a$ & $34.9 \pm 0.3 \dagger * \#$ \\
\hline PCNA Index (\%) Both Testes & $85.5 \pm 1.2$ & $64.8 \pm 0.1 \dagger$ & $64.9 \pm 0.3 \dagger$ & $67.4 \pm 0.1 \dagger^{\mathrm{a}}$ & $34.6 \pm 0.2 \doteqdot \# *$ \\
\hline Numerical Density $(\mu \mathrm{m}-2)$ Left Testis & $0.04 \pm 0.005$ & $0.02 \pm 0.002 \dagger$ & $0.02 \pm 0.002 \Phi$ & $0.04 \pm 0.002 \eta$ & $0.04 \pm 0.005 \eta$ \\
\hline Numerical Density $(\mu \mathrm{m}-2)$ Right Testis & $0.2 \pm 0.02$ & $0.02 \pm 0.003 \dagger$ & $0.03 \pm 0.002 \dagger$ & $0.03 \pm 0.002 \dagger$ & $0.03 \pm 0.003 \dagger$ \\
\hline Numerical Density $(\mu \mathrm{m}-2)$ Both Testes & $0.14 \pm 0.05$ & $0.02 \pm 0.003 \dagger$ & $0.03 \pm 0.002 \dagger$ & $0.04 \pm 0.002 \dagger$ & $0.03 \pm 0.005$ \\
\hline
\end{tabular}

All results presented in mean \pm SEM

$\dagger \mathrm{p}<0.001 ; \Phi \mathrm{p}<0.01 \mathrm{Vs}$ Control; $\# \mathrm{p}<0.001 ; \eta \mathrm{P}<0.01$ Vs Streptozotocin-Insulin;

${ }^{*} \mathrm{p}<0.001$ Vs Streptozotocin-Ginger; ${ }^{\mathrm{a}} \mathrm{p}<0.001$ Vs Insulin resistant-Ginger

$0.4 \mathrm{~mm})$; Streptozotocin-insulin treated rats $(13.2 \pm 0.5 \mathrm{~mm})$; Streptozotocin-ginger treated rats $(13.5 \pm 0.6 \mathrm{~mm})$; Insulin resistant-pioglitazone treated rats $(11.8 \pm 0.6 \mathrm{~mm})$ and Insulin resistant-ginger treated rats $(12.8 \pm 0.6 \mathrm{~mm})$. Testicular diameter was significantly lower $(\mathrm{p}<0.001)$ in all the experimental groups compared to rats in the Control group (Table 1).

PCNA Index (\%) in the left testis was significantly lower $(\mathrm{p}<0.001)$ in the Streptozotocin-insulin treated $(64.5 \pm 0.2 \%)$; Streptozotocin-ginger treated $(65.4 \pm 0.1 \%)$; Insulin resistantpioglitazone treated $(67.3 \pm 0.2 \%)$ and Insulin resistant-ginger treated rats $(34.5 \pm 0.2 \%)$ compared to rats in the control $(82.8 \pm 0.1 \%)$ group. In the right Testis, PCNA was also significantly lower $(\mathrm{p}<0.001)$ in the Streptozotocin-insulin treated $(64.8 \pm 0.1 \%)$; Streptozotocin-ginger treated $(64.5 \pm 0.1 \%)$; Insulin resistant-pioglitazone treated $(67.2 \pm 0.1 \%)$; and Insulin resistant-ginger treated rats $(34.9 \pm 0.3 \%)$ compared to rats in the Control $(88.4 \pm 0.1 \%)$ group. Likewise, PCNA index in both testes was significantly lower $(\mathrm{p}<0.001)$ in the Streptozotocin-insulin treated $(64.8 \pm 0.1 \%)$; Streptozotocinginger treated $(64.9 \pm 0.3 \%)$; Insulin resistant-pioglitazone treated $(67.4 \pm 0.1 \%)$ and Insulin resistant-ginger treated rats $(34.6 \pm 0.2 \%)$ compared to rats in the Control $(85.5 \pm 1.2 \%)$ (Table 2).

Numerical Density (ND) of Seminiferous tubule $\left(\mu \mathrm{m}^{2}\right)$ of the left testis in Control rats was $\left(0.04 \pm 0.005 \mu \mathrm{m}^{-2}\right)$; Streptozotocin-insulin treated rats $\left(0.02 \pm 0.002 \mu \mathrm{m}^{-2}\right)$; Streptozotocin-ginger treated rats $\left(0.02 \pm 0.002 \mu \mathrm{m}^{-2}\right)$; Insulin resistant-pioglitazone treated rats $\left(0.04 \pm 0.002 \mu \mathrm{m}^{-2}\right)$; and Insulin resistant-ginger treated rats $\left(0.04 \pm 0.005 \mu \mathrm{m}^{-2}\right)$. Thus, ND of the left testis was significantly lower $(p<0.01)$ in Streptozotocin-insulin and Streptozotocin-ginger treated rats compared to the rats in Control group while there was no significant difference between the control rats and Insulin resistant-pioglitazone and Insulin resistant-ginger treated rats.

On the other hand, ND of the right testis was significantly lower $(p<0.001)$ in the Streptozotocin-insulin treated rats $\left(0.02 \pm 0.003 \mu^{-2}\right)$; Streptozotocin-ginger treated rats $\left(0.03 \pm 0.002 \mu \mathrm{m}^{-2}\right)$; Insulin resistant-pioglitazone treated rats $\left(0.03 \pm 0.002 \mu \mathrm{m}^{-2}\right)$ and Insulin resistant-ginger treated rats $\left(0.03 \pm 0.003 \mu \mathrm{m}^{-2}\right)$ compared to the control rats $(0.2 \pm 0.02$ $\mu \mathrm{m}-2)$. Likewise, ND of both testes was significantly lower $(\mathrm{p}<0.01)$ in the Streptozotocin-insulin treated rats $(0.02 \pm 0.003$ $\mu \mathrm{m}-2)$; Streptozotocin-ginger treated rats $\left(0.03 \pm 0.002 \mu \mathrm{m}^{-2}\right)$; Insulin resistant-pioglitazone treated rats $\left(0.04 \pm 0.002 \mu \mathrm{m}^{-2}\right)$ and Insulin resistant-ginger treated rats $\left(0.03 \pm 0.005 \mu \mathrm{m}^{-2}\right)$ compared to the control rats $\left(0.14 \pm 0.05 \mu \mathrm{m}^{-2}\right)$ (Table 2).

The immunohistochemical staining of seminiferous tubules in all the groups showed that positive slides for all the groups were reactive i.e. nuclei of the cells were brown coloured stained. Thus are positive for PCNA staining. In Figure 1, all the cell lines were present and no abnormality was detected. In Figure 2, secondary spermatocytes and elongated spermatids were not identified. In addition to this, there was also global necrosis and mild reduction in number of germ cells. In Figure 3, older spermatids were not identified. In addition to this, there was mild reduction in number of germ cells and spermatids. In Figure 4, primary spermatocytes, secondary spermatocytes and older spermatids were not identified. In addition to this, there was also focal necrosis and mild reduction in number of germ cells. In Figure 5, secondary spermatocytes, older and elongated spermatids were not identified. In addition to this, there was also reduction in number of spermatids.

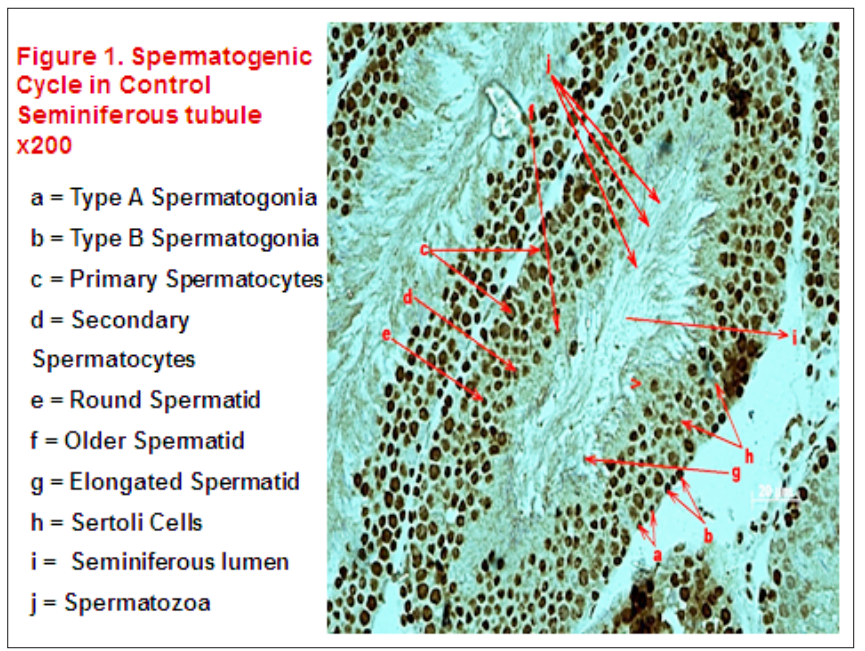

Figure 2. Spermatogenic Cycle in StreptozotocinInsulin Seminiferous tubule $\times 200$

$a=$ Type A Spermatogonia b = Type B Spermatogonia $\mathrm{c}=$ Primary Spermatocytes $\mathrm{d}=\underline{2^{\circ} \text { Spermatocytes not }}$ Identified

e $=$ Round Spermatid $f=$ Older Spermatid

$g=$ Elongated spermatids not Identified

$\mathrm{h}=$ Sertoli Cell

$i=$ Seminiferous lumen

$\mathrm{j}=$ Spermatozoa

I = Leydig cell

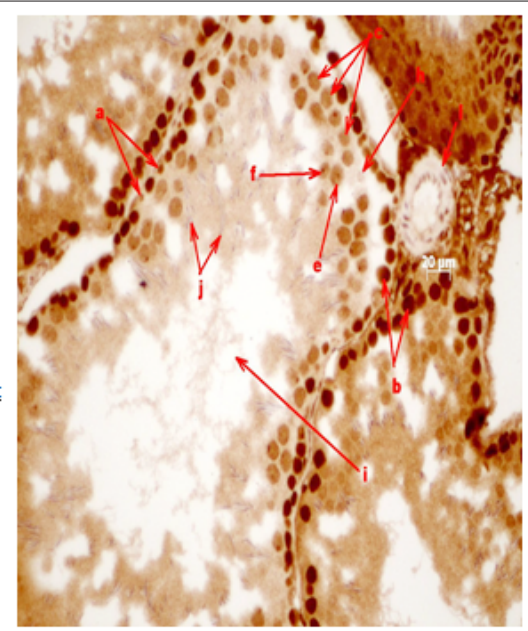



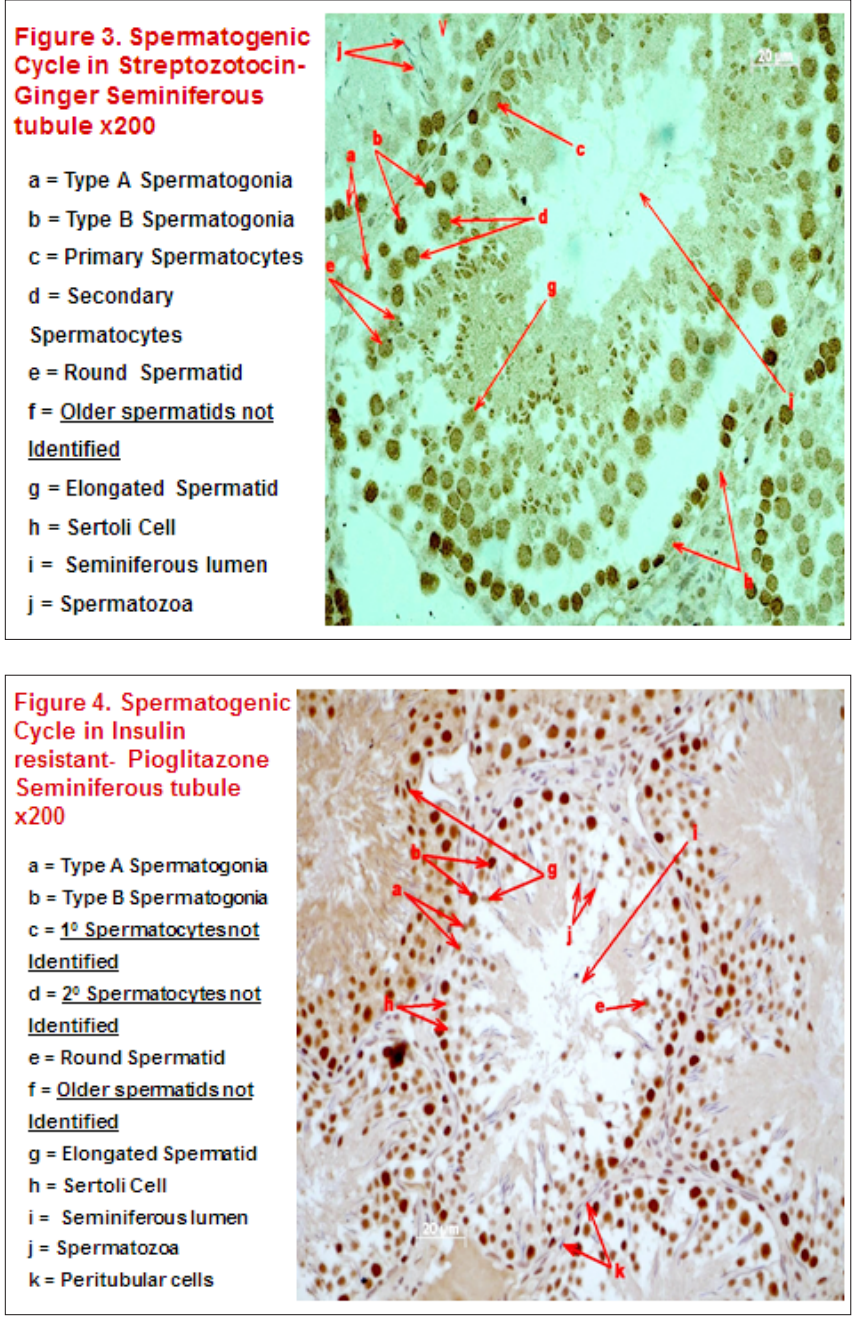

Figure 5. Spermatogenic Cycle in Insulin resistantGinger Seminiferous tubule x200

$a=$ Type A Spermatogonia $\mathrm{b}=$ Type $\mathrm{B}$ Spermatogonia $c=$ Primary Spermatocytes $\mathrm{d}=\underline{2^{0} \text { Spermatocytes not }}$ Identified

$\mathrm{e}=$ Round Spermatid

$\mathrm{f}=\underline{\text { Older spermatids not }}$ Identified $\mathrm{g}=$ Elonqated spermatids not Identified

$\mathrm{h}=$ Sertoli Cell not identified

$\mathrm{i}=$ Seminiferous lumen

$\mathrm{j}=$ Spermatozoa

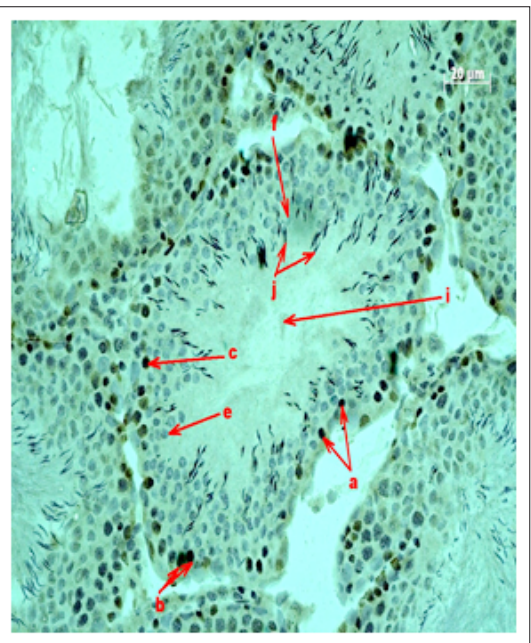

\section{Discussion}

Fasting blood glucose concentration (FBG) and Glycosylated haemoglobin level (HbAlc) were significantly higher $(p<0.001)$ in all the experimental groups compared to rats in the Control group, with the exception in the Insulin resistantpioglitazone treated and Insulin resistant-ginger treated rats, were FBG was not significantly different compared to that of the control rats.

The results on FBG level support the views that streptozotocin increases blood glucose in rats (Altay et al., 2003; Gunelli et al., 2008; Lee et al., 2010; Fernandes et al., 2011) to cause type I diabetes mellitus and that chronic fructose consumption through insulin resistance mechanism causes type II diabetes mellitus (Arikawe et al., 2006). The results also show that ginger exhibits some hypoglyceamic effects (Akhani et al., 2004; Kadnur and Goyal, 2005; Al-Amin et al., 2006; Iranloye et al., 2011). The glycaemic level was well controlled in the control animals ( $\mathrm{HbA} 1 \mathrm{c}<6.5 \%)$ while in all the experimental groups, it was not well controlled (HbA1c $>6.5 \%$ ) (Bonnefont-Rousselot et al., 2000; Punithavathi et al., 2011). The results on both FBG and HbA1c were ameliorated by insulin, pioglitazone and ginger administrations.

PCNA reacts intensely with the nuclei of cells at the preleptotene, leptotene through pachytene stages of spermatogenesis but it does not react with the nuclei of Sertoli cells (Wrobel et al., 1996). This was observed in the positive slides (with primary antibody) for all the groups which were reactive i.e. nuclei of the cells were brown colour stained. Thus, were termed positive for PCNA (Altay et al., 2003). Furthermore, there was necrosis (focal or global) and reduction (mild or moderate) in germ (viable) cells and spermatids in both treated groups compared to the Control group.

MSTD of both testes was significantly lower $(p<0.001)$ in all the experimental groups compared to the Control group. This effect progressed with the duration of the diabetic state and appears to be ameliorated more by ginger administration. This is in line with the view of Fernandes (Fernandes et al., 2011) who reported that vitamin $C$ (an anti-oxidant like ginger) restored seminiferous tubular diameter in streptozotocininduced diabetic male rats.

TD, PCNA index (\%), and ND were also significantly reduced $(\mathrm{P}<0.001)$ in all the rats in the experimental groups compared to the rats in the Control group. This is in line with the view of Altay et al. (2003) and Jelodar et al. (2010). The results confirm that diabetes mellitus and insulin resistance impair spermatogenesis in male rats (Arikawe et al., 2006) and that spermatogenic cell cycle series were decreased in the streptozotocin diabetic and insulin resistant diabetic groups (Arikawe et al., 2012).

Treatment with insulin, pioglitazone and ginger ameliorated some of the effects of diabetes mellitus and insulin resistance on MSTD, PCNA, ND and TD. However, these reversed levels were still significantly lower than the Control levels. This could be because insulin, pioglitazone and ginger are insulin sensitizers (Triplitt et al., 2010) and also because diabetes related testicular effects have been attributed to the lack of insulin (Jelodar et al., 2010).

\section{Conclusion}

The results of this study showed that insulin, pioglitazone and ginger administrations ameliorated the diabetic and insulin resistant effects on spermatogenesis in male rats. The precise interplay of hypothalamic, pituitary and steroid hormones is subject for further study in this group of animals.

\section{Acknowledgements}

The authors wish to thank Mr. Ojerinde Biodun, Mr. Osiagwu Daniel, and Mrs. Awopetu Phil for their technical assistance. 


\section{REFERENCES}

Akhani, S.P., Vishwakarma, S.L., Goyal, R.K., 2004. Anti-diabetic activity of Zingiber Officinale in streptozotocin-induced type I diabetic rats. J. Pharm. Pharmacol. 56, 101-105.

Akingba, A.G., Burnett, A.L., 2001. Endothelial nitric oxide synthase protein expression, localization and activity in the penis of alloxan-induced diabetic rats. Mol. Urol. 5, 189-197.

Al-Amin, Z.M., Thomson, M., Al-Qattan, K.K., Peltonen-Shalaby, R., Ali, M., 2006. Anti-diabetic and hypolipidaemic properties of ginger (Zingiberofficinale) in streptozotocin-induced diabetic rats. Brit J. Nutr. 96, 660-666.

Alnaqeeb, M.A., Thomson, M., Al-Qattan, K.K., et al. 2003. Biochemical and histopathological toxicity of ginger (Zingiber officinale) in rats. Kuwait J. Sci. Eng. 30, 35-48.

Altay, B., Cetinkalp, S., Doganavsargil, B., Hekimgil, M., Semerci, B., 2003. Streptozotocin-induced diabetic effects on spermatogenesis with proliferative cell nuclear antigen immunostaining of adult rat testis. Fertility and Sterility. 80, 828-831.

Arikawe, A.P. and Olatunji-Bello, I.I., 2004. Insulin resistance induced by short term fructose feeding may not affect fertility in female rats. Nigerian Journal of Health and Biomedical Sciences. 3, 17-19.

Arikawe, A.P., Daramola, A.O., Udenze, I.C. 2012. Comparison of Streptozotocin-induced Diabetic and Insulin resistant Effects on Spermatogenesis with Proliferating Cell Nuclear Antigen (PCNA) immunostaining of Adult Rat Testis. J Exp Clin Med. 29, $213-218$.

Arikawe, A.P., Daramola, A.O., Odofin, A.O., Obika, L.F.O., 2006. Alloxan-induced and insulin-resistant diabetes mellitus affect semen parameters and impair spermatogenesis in male rats. Afr. J. Reprod. Health. 10, 106-113.

Bartley, J., Jacobs, A., 2000. Effects of drying on flavour compounds in Australian-grown ginger (Zingiberofficinale). J. Sci. Food Agr. 80, 209215.

Bonnefont-Rousselot, D., Bastard, J.P., Jaudon, M.C., Delattre, J., 2000. Consequences of the diabetic status on the oxidant/antioxidant balance. Diabetes Metab., 26, 163-176.

Bravo, R., Macdonald-Bravo, H., 1987. Existence of two populations of cyclin/proliferating cell nuclear antigen during the cell cycle: Association with DNA replication sites. J. Cell Biol. 105, 1549-1554.

Catena, C., Giacchetti, G., Novello, M., Colussi, G., Cavarape, A., Sechi, L.A., 2003. Cellular mechanisms of insulin resistance in rats with fructose-induced hypertension. Am. J. Hypertens. 16, 973-978.

Colosia, A.D., Marker, A.J., Lange, A.J., el-Maghrabi, M.R., Granner, D.K., Tauler, A., Pilkis, J., Pilkis, S.J., 1988. Induction of rat liver 6-phosphofructo-2-kinase/fructo-2, 6-diphosphate mRNA by refeeding and insulin. J. Biol. Chem. 263, 1866-1877.

Dall'Aglio, E., Reaven, G. M., Azhar, S., 1986. Evidence that insulin deficiency in the rats disparate effects on fructo-2, 6-diphosphate levels in muscle and liver. Endocrinology. 118, 108-111.

Dervan, P. A., Magee, H. M., Buckley, C., Carney, D. N., 1992. Proliferating cell nuclear antigen counts in formalin-fixed paraffin-embedded tissue correlate with ki-67 in fresh tissue. Am. J. Clin. Pathol. 97, 21-28.

Fernandes, G.S., Fernandez, C.D., Campos, K.E., Damasceno, D.C., Anselmo-Franci, J.A., Kempinas, W.D., 2011. Vitamin C partially attenuates male reproductive deficits in hyperglycemic rats. Reprod. Biol. Endocrin. 9, 100.

Gastaldelli, A., Ferrannini, E., Miyazaki, Y., Matsuda, M., Mari, A., DeFronzo, R.A., 2007. Thiazolidinediones improve beta-cell frunction in Type 2 diabetic patients. Am. J. Physiol. Endoc. M. 292, 871-883.

Guneli, E., Tugyan, K., Ozturk, H., Gumustekin, M., Cilaker, S., Uysal, N., 2008. Effect of Melatonin on testicular damage in streptozotocininduced diabetes rats. Eur. Surg. Research, 40, 354-360.

Hugget, A.S.G., Nixon, D.A., 1957. Use of glucose oxidase, peroxidase and O-diamisidine in determination of blood and urinary glucose. Lancet. $1,368-370$.

Iranloye, B.O., Arikawe, A.P., Rotimi, G., Sogbade, A.O., 2011. Anti-diabetic and anti-oxidant effects of Zingiber officinale on alloxan-induced and insulin resistant diabetic male rats. Nig. J. Phsiol. Sci. 26, 89-96.

Jelodar, G., Khaksar, Z., Pourahmadi, M., 2010. Endocrine profile and testicular histomorphometry at puberty in rat offspring from diabetic mothers. Comp. Clin. Pathol. 19, 135-139.

Kadnur, S.V., Goyal, R.K., 2005. Beneficial effects of Zingiber officinale Roscoe on fructose induced hyperlipidemia and hyperinsulinemia in rats. Indian. J. Exp. Biol. 43, 1161-1164.

Kim, D., Jeond, S., and Lee, C. H., 2003. Antioxidant capacity of phenolic phytochemicals from various cultivars of plum. Food Chem. 81, 321-326

Lee, J.H., Yang, S.H., Oh, J.M., Lee, M.G., 2010. Pharmacokinetics of drugs in rats with diabetes mellitus induced by alloxan or streptozotocin: comparison with those in patients with type I diabetes mellitus. J. Pharm. Pharmacol. 62, 1-23.

Linden, M.D., Torres, F.X., Kubus, J., Zarbo, R.J., 1992. Clinical application of morphologic and immunocytochemical assessments of cell proliferation. Am. J. Clin. Pathol. 97, 4-13.

Matthews, D.R., Charbonnel, B.H., Hanefield, M., Brunetti, P., Schernthaner, G., 2005. Long-term therapy with addition of pioglitazone to metformin compared with the addition of gliclazide to metformin in patients with Type 2 diabetes: A randomized, comparative study. Diabetes Metab. Res. 21, 167-174.

Miyazaki, Y., De Fronzo, R.A., 2008. Rosiglitazone and pioglitazone similarly improve insulin sensitivity and secretion, glucose tolerance and adipocytokines in Type 2 diabetic patients. Diabetes Obes.Metab. 10, 1204-1211.

Miyazaki, Y., Mahankali, A., Matsuda, M., Mahankali, S., Hardies, J., Cusi, K., Mandarino, L.J., DeFronzo, R.A., 2002. Effect of pioglitazone on abdominal fat distribution and insulin sensitivity in Type 2 diabetic patients. J.Clin.Endocr. Metab. 87, 2784-2791.

Morakinyo, A.O., Adeniyi, O.S., Arikawe, A.P., 2008. Effects of Zingiber officinale on reproduvtive functions in male rats. Afr. J. Biochem Research. 11, 329-333.

Portnoi, G., Cheng, L.A., Karimi-Tabesh, L., Koren, G., Tan, M.P., Einarson, A,. 2003. Prospective comparative study of the safety and effectiveness of ginger for the treatment of nausea and vomiting in pregnancy. Am. J. Obstet. Gynaecol. 189. 1374-1377.

Punithavathi, V.R., Prince, P.S., Kumar, R., Selvakumari, J., 2011. Antihyperglycaemic, antilipidperoxidative and antioxidant effects of gallic acid on streptozotocin induced diabetic Wistar rats. Eur. J. Pharmacol. 650, 465-471.

Stephan, H., Polzar, B., Rauch, F., Zanotti, S., Ulke, C., Mannherz, H.G., 1996. Distribution of deoxyribonuclease I (DNase I) and p53 in rat testis and their correlation with apoptosis. Histochem. Cell biol. 106, 383-393.

Thomson, M., Al-Qattan, K.K., Al-Sawan, S.M. 2002. The use of ginger (Zingiber officinale Rose) as a potential anti-inflammatory and anti- 
thrombotic agent. Prostagl. Leukoir. Essen. Fatty Acids. 67, 475-478.

Todd Cade, W., 2008. Diabetes-Related microvascular and macrovascular diseases in the physical therapy setting. Phys. Ther. 88, $1322-1335$.

Triplitt, C., Cersosimo, E., De Fronzo, R.A. 2010. Pioglitazone and alogliptin combination therapy in type 2 diabetes: A pathologically sound treatment. Vascular Health and Risk Management, 6, 671-690.

van Dierendonck, J.H., Wijsman, J.H., Keijzer, R., van de Velde, C.J., Cornelisse, C.J., 1991. Cell-cycle-related staining patterns of anti-proliferating cell nuclear antigen monoclonal antibodies. Comparison with BrdUrd labeling and Ki-67 staining. Am. J. Pathol. 138, 1165-1172.

Waseem, N.H., Lane, D.P., 1990. Monoclonal antibody analysis of the proliferating cell nuclear antigen (PCNA). Structural conservation and the detection of a nucleolar form. J. Cell Sci. 96, 121-129.,

Watala, C., Kazmierczak, P., Dobaczewski, M., Przygodzki, T., Bartuś, M., Łomnicka, M., Słomińska, E.M., Durackova, Z., Chłopicki, S., 2009. Antidiabetic effects of 1-methylnicotinamide (MNA) in streptozocin-induced diabetes in rats. Pharmacol. Rep. 61, 86-98.

World Health Organization. Diabetes: The cost of diabetes. 2002 (Facts sheet No. 236).

Wrobel, K.H., Bickel, D., Kujat, R., 1996. Immunohistochemical study of seminiferous epithelium in adult bovine testis using monoclonal antibodies against Ki-67 protein and proliferating cell nuclear antigen (PCNA). Cell Tissue Res. 283, 191-201.

Zeng, L., Kong, X.T., Su, J.W., Xia, T.L., Na, Y.Q., Guo, Y.L., 2001. Evaluation of germ-cell kinetics in infertile patients with proliferating cell nuclear antigen proliferating index. Asian J Androl. 3, 63-66.

Zhao, H., Piao, C., Gong, S., 2004. Diabetic damage to male reproduction and its mechanism. Zhonghua Nan KeXue. 10, 767-770.

Zimmet, P., Alberti, K.G., Shaw, J., 2001. Global and societal implications of the diabetes epidemic. Nature. 414, $782-787$. 